\title{
Dos modelos de democracia radical. Sobre La Constitución Ontológica Del Sujeto Democrático
}

\author{
JUAN ANTONIO GONZÁLEZ DE REQUENA FARRÉ*
}

Resumen: Con el declive del Estado del Bienestar, cuando el posmodernismo cultural y la postmodernización social han llegado a ser tendencias manifiestas, el sentido de la agencia política está cambiando profundamente. Más allá de las perspectivas democráticas tradicionales basadas en la protección de derechos, la elección pública, los procedimientos de decisión, la representación formal, el equilibrio legal o la participación militante, la condición antagónica del sujeto político es actualmente establecida y reivindicada en un sentido radical democrático. En este artículo, comparamos dos modelos de democracia radical y sus formas de construir el sujeto político: un modelo de democracia radical y plural (desarrollado por Ernesto Laclau y Chantal Mouffe) y un modelo de democracia multitudinaria (propuesto por Toni Negri, Michael Hardt y Paolo Virno).

Palabras clave: democracia radical, sujeto político, pluralismo, hegemonía, populismo, postfordismo, biopolitica, multitud.

Abstract: With the decline of the welfare state, when cultural postmodernism and social posmodernizing have become manifest trends, the meaning of the political agency is changing profoundly. Beyond the traditional democratic perspectives based on the protection of rights, the public election, decision-making procedures, the formal representation, the legal balance or militant participation, the antagonistic status of the political subject is currently established and claimed in a radical democratic way. In this article, we compare two models of radical democracy and their ways of constructing the political subject: a model of plural and radical democracy (developed by Ernesto Laclau and Chantal Mouffe) and a model of multitudinous democracy (proposed by Toni Negri, Michael Hardt and Paolo Virno).

Key words: radical democracy, political subject, pluralism, hegemony, populism, post-fordism, biopolitics, multitude.

\section{Introducción: de la democracia participativa, a la democracia radical.}

En el discurso teórico-político de la democracia contemporánea, el léxico de la participación ha ocupado un lugar importante, a la hora de concebir las condiciones de posibilidad para la profundiza-

\footnotetext{
${ }^{*}$ Licenciado en Filosofía y Letras, Universidad Autónoma de Madrid. Magíster en Ciencias Sociales, Universidad Arcis de Chile. Doctorando en Filosofía, Universidad Complutense de Madrid. Correo electrónico: juannelly@surnet.cl
} 
ción y cumplimiento efectivo de nuestras prácticas e instituciones democráticas. No en vano, a través de nuestras tradiciones democráticas, se ha transmitido cierta expectativa reguladora, conforme a la cual la autoinstitución democrática de la sociedad pasa tanto por la extensión de los ámbitos de participación, como por la intensificación del compromiso ciudadano. Desde luego, este ideal de participación democrática tiene una larga historia, que va desde la virtud cívica de los antiguos, pasando por la soberanía popular en la concepción moderna de la democracia, y por la visión de la democracia como desarrollo moral e ilustración pública, hasta la utopía de la democracia directa y de la autogestión de la producción social. Pero es en las propuestas de democracia participativa que surgieron en torno a la década de 1970, donde se encuentra formulado muy explícitamente este principio justificativo, incluso con la pretensión de erigirse en el pilar de todo un modelo de construcción de la sociedad democráti$\mathrm{ca}^{1}$. Hay que señalar que este modelo de democracia participativa exhibe un árbol genealógico complejo: en él, convergen no sólo algunas vías del socialismo democrático y algunas facciones críticas de la democracia liberal, sino también ciertas posiciones vinculadas al republicanismo cívico ${ }^{2}$. Por otra parte, debemos recordar que estas propuestas de democracia participativa surgieron como reacción frente a cierto modelo elitista-pluralista de equilibrio, el cual se limitaba a concebir la democracia como un mecanismo de selección de élites políticas cualificadas, siempre en un marco de competencia poliárquica, como si la política democrática respondiera básicamente a lógica del mercado (y de tal manera que los votantes-consumidores tan sólo escogerían periódicamente a partir de una oferta política autoseleccionada) ${ }^{3}$. Ahora bien, el modelo participativo también se opone frontalmente a las propuestas de democracia legal ultraliberal popularizadas por la nueva derecha, que no sólo consagran el modelo de mercado y la libre competencia, sino que los extrapolan a todos los ámbitos de la vida social, al tiempo que proclaman la urgencia de limitar jurídicamente los usos democráticos del poder estatal ${ }^{4}$.

Pero, ¿cuáles eran las bases fundamentales del modelo participativo y de qué manera han repercutido en las experiencias democráticas actuales? En cierto modo, los teóricos de la democracia participativa retoman algunos aspectos de las concepciones morales de la democracia (como la que encontramos en John Stuart Mill, por ejemplo ${ }^{5}$ ), las cuales establecen que la vida democrática, más que un simple mecanismo de representación y protección de los intereses individuales, constituye un ámbito idóneo para la formación de una ciudadanía capaz de autodesarrollarse mediante la libre participación. Por otra parte, el ideal de participación contempla que el desarrollo de una sociedad participativa exige reducir todas las esferas institucionales que no resulten responsables ante los ciudadanos, pero también requiere mantener estructuras institucionales abiertas, que garanticen la posibilidad de experimentar con formas políticas más participativas ${ }^{6}$. Ahora bien, la expectativa de devolverle a la democracia un horizonte de desarrollo igualitario de la participación - según los teóricos de la democracia participativa - no sólo pasa por lograr un mayor compromiso ciudadano, sino que, además, demanda una reducción de las desigualdades económicas y sociales actuales; y es que no puede haber participación democrática significativa, sin lograr transformaciones decisivas en las formas vigentes de exclusión y

\footnotetext{
${ }^{1}$ Me remito a MACPHERSON, C. B. , La democracia liberal y su época. Madrid, Alianza Editorial, 1982, pp. 112-138. Véase, también, HELD, David, Modelos de democracia. Madrid, Alianza Editorial, 1991, pp. 306-316.

${ }^{2}$ Entre los principales formuladores de este modelo de democracia participativa, se hallan -según Held- autores tan variopintos como Macpherson, Nicos Poulantzas o Carole Pateman. (Modelos de democracia, op. cit. , p. 306).

${ }^{3}$ Véase MACPHERSON, La democracia liberal y su época, op. cit. , pp. 95-112.

${ }^{4}$ A propósito del modelo neoliberal de democracia legal propuesto por la nueva derecha, véase HELD, op. cit. , 292-303.

${ }^{5}$ Me remito a MACPHERSON, op. cit. , pp. 58-94.

${ }^{6}$ Véase HELD, op. cit. , pp. 315- 316. Held sintetiza el principio justificativo del modelo de democracia participativa del siguiente modo: "El derecho igual para todos al autodesarrollo sólo puede alcanzarse en una «sociedad participativa», una sociedad que fomente un sentido de la eficacia política, nutra la preocupación por los problemas colectivos y contribuya a la formación de una ciudadanía sabia, capaz de interesarse de forma continuada por el proceso de gobierno”. (Ibíd. , p. 315).
} 
desigualdad social ( $\mathrm{y}$, a la inversa, si no superamos la apatía política y si no nos comprometemos en la participación democrática, no disminuirán las asimetrías socio-económicas) ${ }^{7}$.

Sin duda, este modelo de democracia participativa tuvo su momento: la irrupción de los nuevos movimientos sociales y el militantismo de clase, justamente cuando se agudizaba la sobrecarga del estado del bienestar y las crisis de legitimación en el capitalismo tardío, entre otras contingencias, le dieron cierto sustento descriptivo a este modelo participativo que, eventualmente, movilizó las expectativas de la nueva izquierda democrática ${ }^{8}$. Sin embargo, a raíz de los procesos de complejización, posmodernización y globalización, que han afectado a las sociedades postindustriales avanzadas, las perspectivas de la nueva izquierda se han desplazado, más allá de las expectativas asociadas al modelo de democracia participativa, hacia proyectos de radicalización de la democracia o modelos de democracia radical (tal y como los que proponen Ernesto Laclau, Chantal Mouffe, Antonio Negri, Michael Hardt o Paolo Virno, entre otros). En términos generales, no es tanto la extensión y homogeneización de la participación política lo que concentra el interés de los actuales modelos de democracia radical, sino que, más bien, su perspectiva teórico-política se centra en la compleja constitución del sujeto político democrático (así como en la redescripción de las identidades políticas), a través de toda la heterogeneidad de las prácticas democráticas y de la multiplicidad de conflictos autónomos que fracturan el espacio público de representación. Ciertamente, los proyectos de democracia radical comparten algunas premisas con el modelo de democracia participativa: en primera instancia, el malestar ante las formas de clausura del espacio de representación socio-político, así como el cuestionamiento de las formas de reducción instrumental o procedimental de lo político, que terminan subordinando la acción política a la circulación, agregación y equilibrio de intereses individuales autosubsistentes (por analogía con el funcionamiento del mercado). Pero coinciden, también, en la percepción de las asimetrías y luchas que surcan las relaciones de poder, y en la iniciativa de profundizar la revolución democrática a través de una gama cada vez más amplia de esferas de la vida social, de manera que las reivindicaciones igualitarias y las garantías liberales se vayan articulando en la trama plural de las prácticas democráticas.

Sin embargo, los proyectos de democracia radical se alejan del modelo de democracia participativa, cuando se trata de concebir la autoinstitución democrática de lo social, así como la relación entre las garantías institucionales liberales y las formas de autogestión democrática de la producción social. No en vano, al sobrestimar las opciones de la apropiación social de la producción y de una autogestión directa de lo social, los teóricos de la democracia participativa parecen reproducir la imagen de una sociedad plena y suturada, de modo que descuidan tanto la autonomía de los espacios políticos y de las prácticas democráticas, como la multiplicidad de las posiciones antagónicas de sujeto que atraviesan el espacio público9 . Además, el llamado a la autogestión social participativa no siempre toma en serio la

\footnotetext{
${ }^{7}$ Véase MACPHERSON, op. cit. , p. 121.

${ }^{8}$ Macpherson describe con precisión el contexto de consolidación del modelo de democracia participativa: "Se inició como consigna de los movimientos estudiantiles de Nueva Izquierda del decenio de 1960. Se difundió entre la clase obrera en los decenios de 1960 y 1970, sin duda como resultado del creciente descontento en el trabajo entre los obreros y los empleados, y de la sensación más generalizada de alienación, que se convirtieron en aquellos años en temas tan de moda para los sociólogos, los expertos en gestión, las comisiones oficiales de investigación y los periodistas populares. Una manifestación de este nuevo espíritu fue el nacimiento de movimientos favorables al control obrero de la industria. En los mismos decenios, la idea de que debería haber una participación considerable de los ciudadanos en la formulación de decisiones por el gobierno se extendió tanto que varios gobiernos nacionales empezaron a hacer suyas, al menos verbalmente, las consignas de la participación, y algunos incluso iniciaron programas que contenían una amplia participación ciudadana". (La democracia liberal y su época, op. cit. , pp. 113114).

${ }_{9}$ Me remito a LACLAU, Ernesto y MOUFFE, Chantal, Hegemonía y estrategia socialista. Hacia una radicalización de la democracia. Madrid, Siglo XXI Editores, 1987, pp.198-202. En una nota a pie de página, los autores sintetizan su principal diferencia con los modelos de democracia participativa: "Aparte del hecho de que nuestra reflexión está ubicada en una problemática teórica muy diferente, nuestro énfasis en la necesidad de articular una pluralidad de formas de democracia correspondientes a una multiplici-
} 
importancia que tienen para la revolución democrática las prácticas, garantías e instituciones políticas liberales; y es que la radicalización de la democracia no consiste en renegar de las posibilidades de la democracia liberal, sino en extenderlas a nuevas luchas y, eventualmente, rearticularlas desde una estrategia hegemónica de izquierda ${ }^{10}$. Por lo demás, el militantismo democrático, que tanto consagran los modelos de democracia participativa, tampoco parece reconocer el carácter post-participativo de algunas formas de resistencia democrática contemporánea, tales como el éxodo, la defección, el derecho de fuga o la desobediencia civil ${ }^{11}$.

En cierto sentido, con la complejización reticular de las sociedades democráticas contemporáneas y debido a la difusión de la conflictividad a relaciones sociales cada vez más numerosas, podemos sostener que se han profundizado los dilemas constitutivos de la democracia liberal, al mismo tiempo que se han descentrado las prácticas democráticas y se han dispersado las posiciones antagónicas de sujeto. La radicalización de la revolución democrática en las sociedades actuales pone de manifiesto una tensión esencial entre los léxicos de autodescripción de las instituciones democráticas (la inconmensurabilidad última del lenguaje de la igualdad democrática y del lenguaje liberal de los derechos individuales) ${ }^{12}$; pero, también, exhibe la aporética e indecidible relación entre, por un lado, la lógica de la equivalencia que regula la construcción democrática del espacio público y, por otra parte, la autonomía y heterogeneidad de las reivindicaciones y posiciones de sujeto ${ }^{13}$. Desde luego, no resulta fácil concebir la articulación de los antagonismos que debe abarcar un proyecto de democracia radicalizada, toda vez que no resulta posible disponer de una "topografía" de los conflictos sociales que nos permitiera determinar a priori las posiciones de sujeto, los niveles de efectividad de la estructura social, así como los lugares y momentos de una ruptura política fundacional ${ }^{14}$. En ese sentido, la revolución democrática, que los proyectos de democracia radical nos instan a profundizar, nos aleja de toda tentación de encontrar un fundamento último o un centro unificador de lo social, en la medida en que los espacios políticos están multiplicándose constantemente a través de la apertura y desplazamiento tanto de las reivindicaciones igualitarias, como de las demandas de libertad, sin que podamos clausurar la organización de lo social. Más allá de todo cierre de un sistema clausurado de diferencias, la radicalización de la revolución democrática nos expone a la multiplicación y transformación constantes en las posiciones antagónicas de sujeto y en las identificaciones colectivas ${ }^{15}$. Por lo demás, esta radicalización de la democracia no constituye una arbitraria apuesta voluntarista, sino la forma de respuesta inmanente y de resistencia reticular que atraviesa las nuevas redes políticas globales; y es que no podemos olvidar que la revolución democrática se emplaza actualmente en una compleja trama descentrada, a saber: a través de ese régimen de biopoder contemporáneo, abocado al control, reproducción e, incluso, virtualización de todas las dimensiones del vivir en común, que no tiene más centro que los pro-

dad de posiciones de sujeto, diferencia nuestro enfoque del de los teóricos de la «democracia participatoria», con los cuales, sin embargo, compartimos muchos puntos importantes". (Ibíd. , p. 201).

${ }_{10}$ Véase MOUFFE, Chantal, El retorno de lo político. Barcelona, Paidós, 1999, pp. 143-147. Véase, también, Hegemonía y estrategia socialista, op. cit. , p. 199.

11 Me remito a NEGRI, Antonio, y HARDT, Michael, Imperio. Barcelona, Paidós, 2002, pp. 199-203. Según Negri y Hardt, actualmente se perfila una forma de republicanismo "nómada": "Aquí volvemos a encontrarnos con el principio republicano en su manifestación primera: la deserción, el éxodo, el nomadismo. (...) Mientras en la modernidad estar en contra frecuentemente significaba una oposición de fuerzas directa y/o dialéctica, en la posmodernidad la actitud de estar en contra bien podría adquirir su mayor efectividad adoptando una forma oblicua o diagonal. Las batallas contra el imperio podrían ganarse a través de la renuncia y la defección. Esta deserción no tiene un lugar; es la evacuación de los lugares del poder”, (Ibíd. , p. 201). Véase, también, VIRNO, Paolo, Gramática de la multitud. Madrid, proyecto editorial Traficantes de sueños, 2003, pp. 71-73.

12 Véase MOUFFE, Chantal, La paradoja democrática. Barcelona, Editorial Gedisa, 2003, pp. 26-27. Véase, también MOUFFE, El retorno de lo político, op. cit. , p. 181.

${ }^{13}$ Me remito a LACLAU y MOUFFE, Hegemonía y estrategia socialista, op. cit. , pp. 205-206.

${ }^{14}$ Véase Hegemonía y estrategia socialista, op. cit. , pp. 201-202.

${ }^{15}$ Ibíd. , pp. 204-208. 
pios márgenes del sistema, y que configura fronteras flexibles e identidades tan híbridas como fluidas ${ }^{16}$.

Ahora bien, a pesar de ciertas convergencias entre las diferentes propuestas contemporáneas de radicalización democrática (sobre todo, al problematizar la constitución ontológica del sujeto político democrático y reconocerle un rol productivo a la multiplicidad de los antagonismos sociales), sin embargo, cabe distinguir dos versiones de un posible modelo de democracia radical: la democracia radical pluralista, que representan Laclau y Mouffe, y, por otra parte, la democracia radical multitudinaria, defendida por Negri, Hardt y Virno. En términos generales, las diferencias más notables entre estos "subtipos" de democracia radical conciernen al modo en que se proyecta la constitución del sujeto político: como construcción de una representación hegemónica e inscripción de un significante (como el "pueblo"), que permite articular las demandas sociales a través de encadenamientos de equivalencias entre las posiciones particulares; o como potencia de la "multitud" y producción en común de una multiplicidad de singularidades, que se sustrae al orden de la representación.

\section{La democracia radical pluralista (Laclau y Mouffe).}

Sin duda, el sentido de la propuesta de Laclau y Mouffe se entiende cabalmente como una incorporación del "giro lingüístico" en la reflexión teórico-política. Estos teóricos de la democracia radical pluralista no sólo se han hecho cargo de la centralidad del discurso en unas relaciones sociales que se consideran lingüísticamente estructuradas, sino que, además, han profundizado la crítica al esencialismo filosófico (a la tentación metafísica de pensar el ser como presencia, y a toda pretensión de acceso a un sentido pleno extradiscursivo) ${ }^{17}$. Por si fuera poco, desde este "giro lingüístico", han radicalizado la deconstrucción de la concepción de un sujeto unitario y fundante, para afrontar el descentramiento y la unificación sólo relativa de nuestra pluralidad de posiciones de sujeto ${ }^{18}$. Así, pues, en este enfoque teórico de la democracia radical, el discurso se perfila como el ámbito constitutivo de la objetividad como tal. Por otra parte, al comprender el discurso como un sistema diferencial, es decir, como juego de diferencias o complejo relacional en el cual todo sentido se explica en tanto que articulación diferencial de los elementos significativos, se establecen las bases para toda una ontología social de corte diferencialista, que deniega cualquier pretensión de reintegrar una totalidad esencial o algún fundamento a priori de lo social, más allá del juego de las diferencias socio-discursivas ${ }^{19}$. Y es que una formación discursiva no consiste sino en cierta regularidad en la dispersión, tal y como queda de manifiesto en cualquier modalidad de construcción y enunciación del sentido; esto es, la constitución del sentido discursivo pasa por la producción regulada de elementos dispersos o, en otros términos, por la articulación de posiciones diferenciales, de manera que no hay ninguna unidad del discurso que pudiéramos hallar en algún a priori trascendental, sujeto fundante o experiencia originaria del sentido ${ }^{20}$. Desde esa perspectiva, no se puede realizar la distinción entre prácticas discursivas y prácticas no discursivas, al margen de la producción discursiva del sentido; tenemos que asumir que todo objeto de nuestra realidad social se construye discursivamente, pues no podría surgir independientemente de alguna superficie discursiva de inscripción ${ }^{21}$. Desde luego, esta construcción discursiva del sentido social tiene una eficacia material decisiva, atribuible tanto al carácter performativo de los actos de habla (en los que el decir conlleva siempre hacer al decir), como al hecho de que toda práctica discursiva cobre sentido únicamente en cierto juego de lenguaje y, por tanto, esté siempre entrelazada mate-

\footnotetext{
16 Véase NEGRI y HARDT, Imperio, op. cit. , pp. 51-53.

${ }^{17}$ Se asume, así, el legado teórico de Wittgenstein, Heidegger y Derrida.

${ }^{18}$ Me remito a LACLAU y MOUFFE, Hegemonía y estrategia socialista, op. cit. , pp. VII y VIII del prefacio.

${ }^{19}$ Véase LACLAU, Ernesto, La razón populista. Buenos Aires, Fondo de Cultura Económica, 2005, pp. 92-93.

${ }^{20}$ Véase LACLAU y MOUFFE, Hegemonía y estrategia socialista, op. cit., pp. 119-120.

${ }^{21}$ Ibíd. , p. 121.
} 
rialmente con el trasfondo de una forma de vida materialmente entretejida ${ }^{22}$. En suma, la articulación discursiva del sentido social no existe únicamente como un hecho lingǘstico, sino que atraviesa todo el espesor material de las instituciones, rituales y prácticas, mediante las cuales se despliega y construye una formación discursiva ${ }^{23}$.

Ahora bien, aunque las relaciones sociales se construyen discursivamente, no cabe totalizar la "sociedad" en tanto que objeto de discurso, como si pudiéramos fijar un sistema de diferencias autolimitado o un conjunto estructural sistemático, al margen de la exterioridad y de la producción diferencial a que están expuestas nuestras prácticas discursivas ${ }^{24}$. De ese modo, nos está vedada cualquier fijación última del sentido de lo social: toda identidad socio-discursiva es únicamente relacional y diferencial (del mismo modo que todo discurso no está nunca plenamente suturado, sino atravesado por la diferencia del sentido y por la tensión entre su necesidad interior y la exterioridad contingente de su inscripción). Eso sí, precisamente porque no puede haber una fijación última del sentido, tiene que haber articulaciones parciales de los significantes sociales; de hecho, toda identidad socio-discursiva es relacional, pero no resulta posible clausurar un sistema relacional de lo social, debido al exceso de sentido de todo significante socio-discursivo, es decir, por la polisemia e intertextualidad que desbordan todo discurso, exponiéndolo a su diferencia y exterioridad constitutivas ${ }^{25}$. Esta imposibilidad de clausura de la sociedad nos revela la precariedad y falta de sutura última en la constitución del sujeto; no en vano, también la categoría de sujeto exhibe el mismo carácter sobredeterminado, polisémico, ambiguo e incompleto, que es propio de cualquier identidad discursiva. En todo caso, no se trata de una absoluta dispersión de posiciones de sujeto (como tampoco de la plena presencia a sí de un sujeto trascendental): la constitución político-discursiva del sujeto se da como construcción de identidades parciales y articulaciones contingentes ${ }^{26}$.

Si toda identidad se construye de modo diferencial, y dado que no existe ningún fundamento extradiscursivo ni un centro estructural fundante que determine en última instancia la eficacia de lo social, entonces hemos de concluir que los horizontes dentro de los cuales las identidades se articulan (por más que resulten indecidibles) han de proceder de la interacción de las propias diferencias sociodiscursivas ${ }^{27}$. Por otra parte, la totalidad que abarca todas las diferencias, el conjunto diferencial que hace posible la significación, sólo parece resultar delimitable a través de la exclusión de algo otro, a partir de un exterior decisivo importado como identificación negativa, que posibilita la equivalencia de diversas posiciones diferenciales; es decir, mediante el rechazo común de cierta identidad excluida ${ }^{28}$. De ahí que toda identidad socio-discursiva sólo pueda constituirse a través de un compleja interacción entre la diferencia y la equivalencia, en virtud de un juego tan indecidible como los propios límites de lo social, los cuales ni permiten un acceso a un más allá exterior a las diferencias discursivas, ni clausuran una plena presencia interior del sentido, sino que dislocan y atraviesan cualquier construcción discursiva de lo social. De esa manera, la sociedad es siempre ya una totalidad fallida ${ }^{29}$.

\footnotetext{
22 Ibíd. , pp. 123-124.

${ }^{23}$ Ibíd. , p. 125.

24 Ibíd. , pp. 129-131.

${ }^{25}$ Sostienen Laclau y Mouffe: "La sociedad no consigue nunca ser idéntica a sí misma, porque todo punto nodal [cualquier significante social clave] se constituye en el interior de una intertextualidad que lo desborda. La práctica de la articulación consiste, por tanto, en la construcción de puntos nodales que fijan parcialmente el sentido; y el carácter parcial de esa fijación procede de la apertura de lo social, resultante a su vez del constante desbordamiento de todo discurso por la infinitud del campo de la discursividad'. (Hegemonía y estrategia socialista, op. cit. , p. 130).

${ }^{26}$ Ibíd. , pp. 140-141.

27 Véase LACLAU, La razón populista, op. cit. , pp. 93-94.

${ }^{28}$ Ibíd. , p. 94.

${ }^{29}$ Véase LACLAU y MOUFFE, Hegemonía y estrategia socialista, op. cit. , pp. 144-147. Laclau ha sintetizado su argumento acerca de la indecidibilidad de los límites e identidades socio-discursivos del siguiente modo: “(...) si el lenguaje es un sistema de diferencias, se requiere lógicamente la sistematicidad de ese sistema para la construcción de cualquier identidad. Esta sistemati-
} 
Sin embargo, en este conjunto indecidible de posiciones diferenciales, puede ocurrir que una diferencia determinada, sin dejar de ser particular, encarne la completud siempre ya fallida de lo social, y posibilite la articulación de una totalización inalcanzable; pero, para ello, ha de transformar su propia particularidad en el significante de la totalidad inconmensurable de lo social ${ }^{30}$. Así, pues, la totalización de un horizonte social depende de un complejo juego de diferencias y equivalencias, esto es, de la identificación equivalencial de las diferentes posiciones y demandas particulares, en torno a algún significante tan puro como vacío (como el significante "pueblo", por ejemplo), sin más significado que el vaciado de la significación particular y que la representación de una plenitud vacía ${ }^{31}$. En ese sentido, la expansión de las cadenas de equivalencias sociales, así como la unificación simbólica de las distintas demandas particulares y posiciones de sujeto, hacen posible constituir la unidad imposible de lo social. Ahora bien, esta investidura totalizadora de lo social, a partir del juego diferencial de las posiciones de sujeto, pasa siempre por cierta operación hegemónica, consistente en la inscripción político-discursiva de un significante vacío. Por lo tanto, no hay sistemas sociales plenamente clausurados y autotransparentes, sino únicamente articulaciones político-discursivas de las relaciones sociales y totalizaciones hegemónicas del campo socio-histórico; no en vano, toda objetivación del orden social se construye político-discursivamente mediante actos y relaciones de $\operatorname{poder}^{32}$. Y es que el establecimiento de vínculos sociales equivalenciales no surge de una convergencia a priori de las distintas posiciones diferenciales, sino que tan sólo emerge de cierta articulación hegemónica; de ese modo, el sujeto político democrático se constituye únicamente mediante la inscripción y nominación discursiva de una sociedad ausente, a través de la propia indeterminación de lo social ${ }^{33}$. En suma, la radicalización de la revolución democrática, a través de toda una gama de relaciones sociales y luchas plurales, requiere de la construcción del sujeto como un agente descentrado, constituido en la interacción de una multiplicidad de posiciones de sujeto, cuya articulación contingente surge únicamente como resultado de prácticas hegemónicas ${ }^{34}$.

cidad depende, no obstante, del establecimiento de los límites del sistema, lo cual requiere que se lo delimite respecto de lo que se encuentra más allá de esos límites. Pero como ese más allá sólo puede consistir en otras diferencias, el sistema (al basarse exclusivamente en identidades diferenciales) no puede determinar si las diferencias que constituyen el «más allá» son internas o externas a él. De esa manera, una indecidibilidad constitutiva penetra toda disposición estructural. Dicho de otro modo: ningún sistema puede estar enteramente protegido, dada la indecidibilidad de sus fronteras (...); pero esto equivale a decir que las identidades dentro del sistema estarán constitutivamente dislocadas y que esta dislocación mostrará su contingencia radical”. (LACLAU, Ernesto, Deconstrucción, pragmatismo, hegemonía, en MOUFFE, Chantal (compiladora) Deconstrucción y pragmatismo. Buenos Aires, Paidós, 1998, pp. 111-112).

${ }^{30}$ Véase LACLAU, La rąón populista, op. cit. , p. 95.

${ }^{31}$ Ibíd. , p. 107.

${ }^{32}$ El concepto de hegemonía, de raigambre marxista y concretamente gramsciana, resulta redescrito en clave político-discursiva, toda vez que no se reconocen posiciones y roles sociales estructuralmente determinados a partir de alguna "topografía" de lo social. Según Mouffe, cualquier ordenamiento social depende de una operación hegemónica: "Ello implica que cualquier objetividad es en último término política y que debe llevar las marcas de la exclusión que gobierna su constitución. Este punto de convergencia, o más bien de mutua reducción, entre la objetividad y el poder es lo que entendemos por «hegemonía». Esta forma de plantear el problema indica que el poder no debería ser concebido como una relación externa que tiene lugar entre dos identidades ya constituidas, sino más bien como el elemento que constituye las propias identidades. Dado que cualquier orden político es la expresión de una hegemonía, de una pauta específica de relaciones de poder, la práctica política no puede ser concebida como algo que simplemente representa los intereses de unas identidades previamente constituidas, al contrario, se tiene que entender como algo que constituye las propias identidades y que además lo hace en un terreno precario y siempre vulnerable". (La paradoja democrática, op. cit. , pp. 112-113).

${ }^{33}$ Me remito a LACLAU, La rąón populista, op. cit. , p. 149.

${ }^{34}$ Sostiene Mouffe: "Para poder pensar hoy la política y comprender la naturaleza de estas nuevas luchas y la diversidad de las relaciones sociales que la revolución democrática ya ha desplegado, es indispensable desarrollar una teoría del sujeto como agente descentrado, destotalizado, de un sujeto construido en el punto de intersección de una multiplicidad de posiciones subjetivas entre las que no hay ninguna relación a priori o necesaria y cuya articulación es consecuencia de prácticas hegemónicas. En consecuencia, nunca hay una identidad definitivamente establecida, sino siempre un cierto grado de apertura y de ambigüedad en la manera de articularse las diferentes posiciones subjetivas". (El retorno de lo político, op. cit. , pp. 31-32). 
Ahora bien, la investidura hegemónica de lo social, esto es, la inscripción de un significante vacío y la construcción de un encadenamiento de equivalencias a través de la pluralidad de las posiciones de sujeto, únicamente lleva a cabo una estabilización parcial, pues la homogeneización simbólica de las diferencias siempre se mantiene expuesta a la dislocación. No en vano, el espacio social de representación está siempre ya interrumpido por toda una gama de antagonismos plurales, los cuales trazan los límites internos que le impiden a la sociedad constituirse como una realidad objetivamente dada y como un sistema autoclausurado ${ }^{35}$. El antagonismo y el conflicto resultan, por tanto, constitutivos no sólo en cualquier ordenamiento social, sino, también, en la inscripción política de un "nosotros" o en la articulación hegemónica de una matriz democrática ${ }^{36}$. De hecho, la construcción de una cadena de equivalencias pasa por la referencia común negativa a algo otro, y depende de la proliferación de esos puntos de ruptura que desplazan constantemente las fronteras internas de lo social ${ }^{37}$. Pero es tal la heterogeneidad de las demandas sociales, que apenas se dejan inscribir en un único encadenamiento estructural de equivalencias, de manera que el sentido de cada demanda parece permanecer indeciso y en suspenso, entre fronteras equivalenciales alternativas. Así, pues, la lógica de la equivalencia resulta siempre dislocada a través de la multiplicación de los puntos de lucha y debido a los desplazamientos de las fronteras antagónicas, dimensiones que todo ordenamiento político procura articular hegemónicamente. En el seno de lo político, se establece, por tanto, una tensión irreducible: por un lado, la lógica de la equivalencia lleva a cabo la subordinación y homogeneización de las demandas particulares; pero, en la medida en que no puede lograrse la homogeneidad pura de un espacio de representación social transparente (ya que la heterogeneidad fractura constantemente cualquier matriz social), entonces, la lógica de la diferencia y la autonomía, de las cuales se sigue la especificidad diferencial de cada lucha, desbaratan cualquier intento de totalización y fijación definitivas del orden social ${ }^{38}$. De hecho, la constitución de las fronteras políticas se halla inevitablemente expuesta a un desplazamiento constante y a una reconfiguración de las demandas particulares y de las posiciones de sujeto, a causa de las fracturas y rearticulaciones antagónicas del espacio de representación social. En ese sentido, el encadenamiento equivalencial de las demandas, así como la representación de una plenitud ausente de lo social, dependen de la inscripción discursiva de algún significante flotante, el cual cumple la función de expresar la articulación antagónica del sentido social, al registrar las dislocaciones y apropiaciones estratégicas de las fronteras sociales ${ }^{39}$. Podemos sostener que, si los significantes vacíos surgían de la universalización de un término particular vaciado de su sentido, los significantes flotantes emergen mediante la apropiación estratégica de algún término equivalencial cuyo sentido permanece antagónicamente indecidido (como si los significantes vacíos, a diferencia de los flotantes, operaran dentro de límites socio-discursivos no expuestos al antagonismo) ${ }^{40}$. Y, así como los significantes vacíos eran articulados en virtud de una operación hegemónica, también los significantes flotantes han de resultar inscritos mediante luchas político-discursivas, toda vez que su sentido permanece suspendido entre demandas heterogéneas y fronteras equivalenciales alternativas.

Así, pues, desde la perspectiva democrática radical, lo político surge de cierto juego indecidible entre lo vacío y lo flotante de los significantes sociales, entre la homogeneización y la heterogeneidad

\footnotetext{
${ }^{35}$ Véase LACLAU y MOUFFE, Hegemonía y estrategia socialista, op. cit. , pp. 145-147.

${ }^{36}$ Según Mouffe: "La vida política concierne a la acción colectiva, pública; apunta a la construcción de un «nosotros» en un contexto de diversidad y de conflicto. Pero para construir un «nosotros» hay que distinguirlo del «ellos», y eso significa establecer una frontera, definir un «enemigo». En consecuencia, mientras la política apunte a la construcción de una comunidad política y a crear una unidad, será irrealizable una comunidad política completamente inclusiva y una unidad final, pues siempre habrá un «exterior constitutivo», algo externo a la comunidad y que la hace posible. Las fuerzas antagónicas nunca desaparecerán, pues el conflicto y la división son inherentes a la política". (El retorno de lo político, op. cit. , pp. 100-101).

37 Véase LACLAU y MOUFFE, Hegemonía y estrategia socialista, op. cit. , pp. 148-150 y 165.

${ }^{38}$ Ibíd. , pp. 205-207.

${ }^{39}$ A propósito de los significantes flotantes, véase LACLAU, La rąón populista, op. cit. , pp. 163-197.

${ }^{40}$ Ibíd. , pp. 165-168.
} 
de los espacios de representación social: por una parte, asistimos a la formación de cadenas de equivalencias entre las demandas sociales, así como se da una homogeneización simbólica de la representación social, por medio de la producción de significantes vacíos; pero, por otra parte, el espacio de representación social se halla constantemente fracturado por la irrupción de demandas heterogéneas, que, al articularse en significantes flotantes, desplazan las fronteras antagónicas y reconfiguran las posiciones de sujeto ${ }^{41}$. En ese sentido, desde un proyecto de democracia radical y plural, lo político consiste tanto en la constitución de fronteras antagónicas en el seno de lo social, cuanto en la convocatoria a la identificación de nuevos sujetos de cambio social, mediante la inscripción de significantes que permitan unificar en cadenas de equivalencias la pluralidad de las demandas sociales ${ }^{42}$. En suma, la democracia radical y plural presupone la creación de equivalencias entre las diferentes luchas democráticas, así como la constitución de identidades comunes entre los sujetos democráticos; pero, también, pasa por asumir que la construcción de un "nosotros" político sólo puede darse en un contexto de diversidad y conflicto, a partir de decisiones antagónicas que fracturan toda homogeneización del espacio social de representación, y desbordan cualquier ilusión de consenso pleno ${ }^{43}$.

Ahora bien, en la inscripción político-discursiva de los sujetos políticos, cabe distinguir diferentes tipos de posición de sujeto. En la posición democrática de sujeto, los antagonismos y luchas proliferan, irrumpiendo de modo puntual y autónomo. En la posición popular de sujeto, las luchas tienden a encadenarse equivalencialmente de modo que el espacio político se divide en dos campos antagónicos: un polo popular que se enfrenta a un enemigo definido, una forma de dominación localizada ${ }^{44}$. Pues bien, esta encrucijada en los modos de construcción hegemónica del sujeto político nos permite comprender las diferencias de énfasis entre los principales teóricos de la democracia radical y plural. Por una parte, resulta patente que el interés de Chantal Mouffe se centra en la profundización y extensión de la revolución democrática, a través de la multiplicación de las prácticas, luchas y posiciones democráticas de sujeto. De hecho, - para Mouffe- la democracia radical y plural sólo podrá crear una nueva hegemonía que resulte de la articulación del mayor número posible de luchas democráticas, si es que asume como matriz democrática la existencia de la pluralidad irreducible y del antagonismo constitutivo ${ }^{45}$. Este "pluralismo agonístico" que Mouffe defiende concibe al sujeto político como una instancia constituida por la intersección de una multiplicidad de identificaciones, antagonismos, posiciones subjetivas e identidades colectivas, las cuales se subvierten y se confrontan entre $\mathrm{s}^{46}$. Por otra parte, los intereses teórico-políticos de Laclau giran en torno a la construcción de la posición de sujeto popular y a la lógica social del populismo; no en vano, Laclau estima que la operación política por antonomasia consiste en la construcción político-discursiva de un pueblo. Y es que, si la democracia depende de la existencia de un sujeto democrático, el cual se constituye mediante la articulación de las demandas equivalentes, a través de un significante vacío como "pueblo", entonces cabe afirmar que la democracia depende de la construcción de un pueblo y de una identidad popular democrática ${ }^{47}$. En ese sentido, las posiciones del sujeto político democrático están siempre sobredeterminadas, a través de los encadenamientos equivalenciales de las demandas sociales y frente a formas de dominación localizables; en consecuencia, las identidades democráticas resultan articuladas e investidas en el significante "pueblo", es decir, en tanto que posición de sujeto popular. Por eso, el populismo sería -según

\footnotetext{
${ }^{41}$ Me remito a LACLAU, La rąón populista, op. cit. , pp. 192-193.

42 Ibíd. , p. 195.

${ }^{43}$ Véase MOUFFE, El retorno de lo político, op. cit. , pp. 100-101.

${ }^{44}$ Me remito a LACLAU y MOUFFE, Hegemonía y estrategia socialista, op. cit. , p. 152.

45 Véase MOUFFE, El retorno de lo político, op. cit. , pp. 22-25. También, MOUFFE, La paradoja democrática, op. cit. , p. 32.

46 Véase MOUFFE, El retorno de lo politico, op. cit. , p. 137.

${ }^{47}$ Véase LACLAU, La razón populista, op. cit. , pp. 213-215. Según Laclau: “(...) la democracia sólo puede fundarse en la existencia de un sujeto democrático, cuya emergencia depende de la articulación vertical entre demandas equivalenciales. Un conjunto de demandas equivalenciales articuladas por un significante vacío es lo que constituye un «pueblo». Por lo tanto, la posibilidad misma de la democracia depende de la constitución de un «pueblo» democrático". (Ibíd. , p. 215).
} 
Laclau - la vía privilegiada para comprender la constitución ontológica de lo político, a saber: la construcción social contingente, a través de la articulación hegemónica, tanto de las identificaciones como de las divisiones sociales, las cuales configuran la totalidad fallida de lo socio-político, y exhiben su indecidibilidad radical ${ }^{48}$.

\section{La democracia radical multitudinaria (Negri, Hardt y Virno).}

Las propuestas de democracia radical de Negri, Hardt y Virno sustentan su comprensión de la constitución del sujeto político, sobre el modo de producción inmanente de la realidad social ${ }^{49}$. En ese sentido, determinar la constitución ontológica de lo político presupone tanto cierta periodización de las tendencias históricas de la sociedad capitalista, para establecer la fase actual en la producción de lo social; cuanto la deconstrucción de esa abstracción real que es la forma-valor (o sea la ley del valor que regula la forma de equivalencia en las relaciones e intercambios sociales), de manera que se logre poner de manifiesto la construcción y representación materiales de los procesos de trabajo, de los modos de consumo y de los modelos de organización ${ }^{50}$.

Pues bien, en la periodización de las tendencias históricas de la sociedad capitalista, los teóricos de la democracia radical multitudinaria consideran decisivo el paso del fordismo al postfordismo, a la hora de dar cuenta de la fase actual de la constitución de lo social ${ }^{51}$. Si la revolución industrial de la que Marx fue testigo se caracterizó por la sujeción de la fuerza de trabajo del obrero profesional, al servicio de la maquinaria productiva, así como por la producción masiva orientada a la acumulación del capital y por la tendencia a la concentración monopolista y al desarrollo imperialista; el periodo fordista de la gran industria (que se extiende desde la Primera Guerra Mundial, hasta los movimientos sociales de 1968) presenta los siguientes rasgos centrales: la irrupción de un "obrero-masa", cuya fuerza de trabajo resulta cada vez más descualificada y abstracta (debido al montaje en cadena y a la organización científica del trabajo), la adecuación del salario al consumo de bienes de producción masiva y, finalmente, el intervencionismo estatal, dirigido a regular la producción colectiva y a garantizar el bienestar social. Ahora bien, a partir de la década de 1970, habría empezado a configurarse un nuevo paradigma de la producción social, el "postfordismo", que coincide con la automatización creciente de la producción y con la informatización de la sociedad; en ese contexto, emerge la figura de un "obrero social", esto es, toda una red colectiva de producción, basada en la información, la comunicación y la cooperación social, de manera que el trabajo se torna inmaterial, abstracto, intelectual (flexible y móvil

\footnotetext{
${ }^{48}$ Laclau resume la construcción populista del sujeto democrático, de la siguiente manera: "La emergencia del pueblo depende de las tres variables que hemos aislado: relaciones equivalenciales representadas hegemónicamente a través de significantes vacíos; desplazamientos de las fronteras internas a través de la producción de significantes flotantes; y una heterogeneidad constitutiva que hace imposibles las recuperaciones dialécticas y otorga su verdadera centralidad a la articulación política. Con esto hemos alcanzado una noción plenamente desarrollada del populismo". (La rąón populista, op. cit. , p. 197).

${ }^{49}$ Se asume, por tanto, que la radicalización de la democracia concierne no tanto a los mecanismos de representación y a los procedimientos formales, cuanto a la producción sustantiva de la vida en común. En palabras de Hardt y Negri: "La democracia no sólo es cuestión de estructuras y relaciones formales, sino también de contenidos sociales, de cómo nos relacionamos los unos con los otros, de cómo producimos juntos". (HARDT, Michael, y NEGRI, Antonio, Multitud. Barcelona, Random House Mondadori, colección "Debolsillo", 2006, p. 123).

50 Acerca de la importancia metodológica de la periodización histórica y de la relevancia de la abstracción real, me remito a HARDT, Michael, y NEGRI, Antonio, Multitud, op. cit. , pp. 172-182. Con respecto a la forma-valor como construcción y representación material de la constitución de lo social, véase NEGRI, Antonio, Interpretación de la situación de clase hoy: Aspectos metodológicos, en NEGRI, Antonio, y GUATTARI, Felix, Las verdades nómadas \& General Intellect, poder constituyente, comunismo. Madrid, Akal, 1999, pp. 84-85.

${ }^{51}$ La periodización del desarrollo capitalista y el tránsito del fordismo al postfordismo se encuentran desarrollados en NEGRI, Antonio, Interpretación de la situación de clase hoy: Aspectos metodológicos, en NEGRI, Antonio, y GUATTARI, Felix, Las verdades nómadas \& General Intellect, poder constituyente, comunismo, op. cit. , pp. 89-91. Véase, también, NEGRI, Antonio, Guías. Barcelona, Paidós, 2004, pp. 50-56.
} 
en su forma $)^{52}$. Este periodo postfordista de la producción social se caracteriza, además, por la globalización de los flujos mercantiles, así como por la segmentación e individualización de los consumos. Y, en lo que concierne a los modelos de regulación de la producción social, asistimos a la construcción de una tupida red de biopoderes, la cual radicaliza el alcance de los dispositivos de poder, hasta el punto de realizar una "sociedad de control", que no se limita a disciplinar la fuerza de trabajo y a tornar dóciles los cuerpos, pues se hace cargo de todos los aspectos de la reproducción de la vida en común (intelecto, afectos, lenguaje, sociabilidad, etc. $)^{53}$. Por lo demás, esta red de biopoder ha adquirido actualmente la figura de un nuevo orden mundial imperial, que no sólo se basa en regulaciones reticulares de los flujos de los capitales trasnacionales, en las mediaciones políticas internacionales y en la irrupción de instituciones supranacionales, sino que, además, resulta garantizado mediante el estado de guerra global, con todo lo que ello implica: movilización total biopolítica, estado de excepción global y amenaza de exterminio masivo ${ }^{54}$.

Sin duda, el tránsito del fordismo al postfordismo constituye la expresión de transformaciones decisivas en la forma-valor y en las modalidades de sujeción del trabajo al capital. De partida, en la actual fase posfordista del capital, la ley del valor se halla en crisis, toda vez que ya no puede establecerse una medida objetiva de equivalencia, tanto para el trabajo abstracto como para los intercambios sociales, que se pudiera determinar en unidades mensurables y homogéneas del tiempo de trabajo socialmente necesario ${ }^{55}$. Y es que, actualmente, el valor carece de medida, y la acumulación social se torna inconmensurable, toda vez que el trabajo deviene flexible (sin una jornada fija), móvil (al margen del lugar de trabajo) e inmaterial (más allá de toda rutina mecánica repetible); no en vano, la producción social postfordista se vincula a la potencialidad intelectual y lingüística genéricas, así como a la creatividad biopolítica, es decir, a la generación inmediatamente social de cooperación y vida en común ${ }^{56}$. Por otra parte, el modo de producción postfordista ha consumado el paso de la subsunción formal, a la subsunción real del trabajo bajo el capital: si la gran industria requería de la movilización forzosa y del encuadramiento disciplinario, con el fin de extraer plusvalía y sujetar la fuerza de trabajo a la producción capitalista; actualmente, la acumulación del valor se lleva a cabo de modo inmediato en todas las dimensiones de la vida social, a través la flexibilidad, movilidad e inmaterialidad de una producción que se basa en el intelecto general, la cooperación y la comunicación ${ }^{57}$. Por tanto, en la fase actual, se ha consumado la subsunción real del trabajo social a la acumulación global de valor, de manera que las relaciones capitalistas de producción son indisociables de las fuerzas sociales producti-

\footnotetext{
52 Este "obrero social" es tanto intérprete, como asistente de la producción de lo común; en suma, un "virtuoso" de las redes de cooperación, de la interacción lingüística y del intelecto general (el marxiano General Intellect). Se trata del protagonista de un nuevo paradigma de producción inmaterial, que Hardt y Negri describen por oposición a la producción de medios materiales: "La producción material - por ejemplo, de coches, televisores, prendas de vestir y alimentos-crea los medios de la vida social. Las formas modernas de la vida social no serían posibles sin esos artículos. En cambio, la producción inmaterial, que incluye la producción de ideas, imágenes, conocimientos, comunicación, cooperación y relaciones afectivas, tiende a crear, no los medios de la vida social, sino la vida social misma”. (HARDT, Michael, y NEGRI, Antonio, Multitud, op. cit. , p. 177).

${ }^{53}$ Me remito a NEGRI, Antonio, y HARDT, Michael, Imperio, op. cit. , pp. 37-44.

${ }^{54}$ Me remito a HARDT, Michael, y NEGRI, Antonio, Multitud, op. cit. , pp. 208 y 13.

55 Véase NEGRI, Antonio, Interpretación de la situación de clase hoy: Aspectos metodológicos, en NEGRI, Antonio, y GUATTARI, Felix, Las verdades nómadas \& General Intellect, poder constituyente, comunismo, op. cit. , pp. 85-87.

${ }_{56}$ Me remito a HARDT, Michael, y NEGRI, Antonio, Multitud, op. cit. , pp. 176-180. Desde el punto de vista de Negri: "Estamos, pues, en una situación en la que, por un lado, el tiempo de trabajo, y, por otro lado, el criterio de medición de este tiempo (y la ley del valor, por tanto) dejan de ser elementos centrales, cuantificadores, de la producción. Será un individuo más bien social y colectivo quien determinará el valor de la producción, dado que, al estar organizado el trabajo en formas comunicativas y lingüísticas, y siendo el saber algo cooperativo, la producción dependerá cada vez más de la unidad de conexiones y relaciones que constituyen el trabajo intelectual y lingüístico, es decir, de este individuo colectivo". (NEGRI, Antonio, Guías. Barcelona, Paidós, 2004, p. 76).

${ }^{57}$ Véase NEGRI, Antonio, y HARDT, Michael, Imperio. Barcelona, Paidós, 2002, pp. 237-238.
} 
vas; pero, precisamente porque la acumulación de valor infiltra reticularmente toda la producción social, la propia forma-valor se torna inconmensurable ${ }^{58}$.

En la medida en que el modo de producción postfordista convierte tanto el saber abstracto y el intelecto general, como la comunicación y la cooperación lingüística, en fuerzas productivas centrales, se disloca la distinción entre "trabajo" y "no trabajo"; tanto dentro como fuera del trabajo, se desarrolla la misma productividad, siempre a partir del ejercicio de facultades intelectuales genéricas, como el lenguaje, el aprendizaje o la sociabilidad ${ }^{59}$. Así, pues, bajo el postfordismo, la producción social prosigue incluso cuando no se trabaja, como una actividad "sumergida" de cooperación social y cultivo cotidiano de capacidades comunicativas y afectivas ${ }^{60}$. Y es que esta productividad social genérica, que es propia del intelecto general, radica en el trabajo vivo de la interacción lingüística, en la acción comunicativa y la empatía relacional; esto es, en una nueva intelectualidad de masas que atraviesa todos los aspectos de la experiencia vital ${ }^{61}$. Ahora bien, cuando la producción social deviene cultivo del intelecto general y ejercicio cotidiano de la acción comunicativa, podemos decir que la praxis virtuosa, la actividad pública que se ejerce sin más fin que la ejecución no instrumental de la cooperación social y la interacción lingüística, se convierte en prototipo del trabajo postfordista ${ }^{62}$. De ese modo, se desdibujan los límites que tradicionalmente se establecían entre trabajo productivo, acción práctico-política y cultivo intelectual; de hecho, bajo el postfordismo, el trabajo no sólo se presenta directamente como intelectualidad de masas, sino, también, como acción política, esto es, en tanto que exposición interhumana e iniciativa plural contingente ${ }^{63}$. De ahí que, actualmente, lo político invista de modo inmanente la producción de lo social, y la constituya radicalmente a través de la continuidad de lo social y lo político ${ }^{64}$.

Cuando el control político recorre todos los tejidos de la vida social, de modo tal que el gobierno de la vida, la producción y reproducción de la vida en común, termina formando parte del campo del poder, entonces entramos en el terreno de la biopolítica ${ }^{65}$.Por una parte, nos encontramos con que, actualmente, se despliega toda una red de biopoderes, a través de los cuales se ejerce un exhaustivo control político sobre la vida, por medio de dispositivos, tecnologías y estructuras de dominación; por otra parte, descubrimos que las transformaciones de la producción social, ligadas a la fase postfordista de reproducción tanto de la cooperación, como de la vida en común, abren nuevas experiencias de subjetivación, nuevas relaciones y luchas sociales, es decir, toda una biopolítica ${ }^{66}$. No en vano, bajo

58 Véase NEGRI, Antonio, Interpretación de la situación de clase hoy: Aspectos metodológicos, en NEGRI, Antonio, y GUATTARI, Felix, Las verdades nómadas \& General Intellect, poder constituyente, comunismo, op. cit. , p. 86.

${ }^{59}$ Me remito a VIRNO, Paolo, Gramática de la multitud, op. cit. , pp. 108-109.

${ }^{60}$ Ibíd. , p. 110.

${ }^{61}$ Ibíd. , pp. 112-115. Según Virno, el General Intellect comprende prácticamente todos los aspectos lingüístico-relacionales de la producción cooperativa de lo común: "El «intelecto general» comprende, por lo tanto, conocimientos formales e informales, imaginación, inclinaciones estéticas, mentalidad, «juegos lingüísticos». En los procesos laborales contemporáneos, somos pensadores y discursos que funcionan de por sí como «máquinas» productivas, sin que deban adoptar un cuerpo mecánico ni tampoco un alma electrónica". (Ibíd. , p. 112).

${ }^{62}$ En ese sentido, los trabajadores postfordistas interpretan cierta "partitura” de cara a los otros: “(...) la partitura sui generis del trabajo contemporáneo es el Intelecto en tanto que Intelecto público, general intellect, saber social global, competencia lingüística común”. (VIRNO, Paolo, Virtuosismo y revolución. Madrid, proyecto editorial Traficantes de sueños, 2003, pág. 95). Véase, también, VIRNO, Gramática de la multitud, op. cit. , pp. 50-56.

${ }^{63}$ Véase VIRNO, Gramática de la multitud, op. cit. , pp. 49-50.

${ }^{64}$ Véase NEGRI, Antonio, Interpretación de la situación de clase hoy: Aspectos metodológicos, en NEGRI, Antonio, y GUATTARI, Felix, Las verdades nómadas \& General Intellect, poder constituyente, comunismo, op. cit. , pp. 112-113.

${ }^{65}$ Me remito a NEGRI, Antonio, Guías, op. cit. , pp. 83-89.

${ }^{66}$ Hardt y Negri remarcan la diferencia entre "biopoder" y "biopolítica", del siguiente modo: "Con anterioridad hemos hablado de «biopoden» para explicar cómo el régimen actual de guerra no sólo nos amenaza con la muerte sino que gobierna la vida produciendo y reproduciendo todos los aspectos de la sociedad. Ahora pasaremos del biopoder a la producción biopolítica. El uno y la otra afectan a toda la vida social, de ahí el común prefijo «bio», pero lo hacen de manera muy diferente. El biopoder está situado por encima de la sociedad, trascendente, a título de autoridad soberana que impone su orden. En cambio, la pro- 
el modo de producción postfordista, tiene lugar la constitución inmanente de una nueva figura de la ontología social, a saber: un cuerpo biopolítico colectivo, que se sostiene en la producción y reproducción de la vida en común, o, en otras palabras, una nueva experiencia biopolítica de la subjetividad, que se forja a través del intelecto y la comunicación inmediatamente sociales ${ }^{67}$. Ahora bien, esta producción inmaterial y biopolítica de lo social está expuesta a su propia deconstrucción, así como a la irrupción de resistencias y luchas de un nuevo cuño; y es que, a las formas de explotación del trabajo postfordista, a la expropiación y apropiación privada de lo común, corresponden experiencias de antagonismo y de producción antagónica de subjetividad, que trazan líneas de fuga a través de las redes de biopoderes $^{68}$. De hecho, la experiencia contemporánea de una subjetividad antagónica surge desde la intelectualidad de masas y desde la producción social de lo común, como una red abierta y expansiva que permite la expresión plural de las singularidades y las diferencias internas (de cultura, raza, género, trabajo, etc.); ese sujeto multiforme, la multiplicidad social que no se deja reducir a la unidad, no es otro que la multitud ${ }^{69}$. La multitud, que protagoniza tanto la producción biopolítica de lo común, cuanto la expansión de la colaboración en la multiplicidad social, no sólo corresponde a la potencia productiva del trabajo postfordista (al intelecto general, así como a la red abierta y distribuida de cooperación lingüística); también expresa la potencia constituyente capaz de crear una transformación democrática radical ${ }^{70}$.

En la medida en que la producción histórico-social deviene potencia biopolítica de la multitud (así como intelectualidad de masas y competencia comunicativa genérica), podemos sostener que, en la fase actual, se torna posible el despliegue de una auténtica "historia natural" de la humanidad. De hecho, la producción histórico-social se hace cargo inmediatamente del invariante biológico y de las facultades humanas genéricas (lenguaje, afectividad, aprendizaje, sociabilidad, etc.), al mismo tiempo que la experiencia humana exhibe marcadamente nuestra incompletud congénita, esto es, la desambientación, flexibilidad, movilidad, plasticidad y adaptabilidad, que nos son connaturales ${ }^{71}$. Así, pues, la fase histórica actual del proceso productivo, el postfordismo, coincide tanto con el protagonismo de las facultades biológicas, como con la manifestación explícita de nuestra antropogénesis, al revivir el proceso de devenir humanos, hablando y cooperando ${ }^{72}$. En ese sentido, la constitución ontológica de la multitud postfordista constituye un fenómeno histórico-natural, en tanto que manifestación antropogenética y expresión multiforme de la intelectualidad genérica, de la facultad comunicativa común y de la potencia inmanente de la sociabilidad ${ }^{73}$.

En los análisis socio-históricos emprendidos por los teóricos de la democracia radical multitudinaria, la fuerza de trabajo postfordista se presenta como intelectualidad de masas y potencia de la multitud. Ahora bien, cabe distinguir tres planos en esta problematización de la multitud: en primer lugar, la descripción socio-histórica de un modo de producción biopolítico centrado en el intelecto general y encarnado en la multitud; en segundo lugar, la constitución ontológica de la multitud como

ducción biopolítica es inmanente a la sociedad y crea relaciones y formas sociales a través de las formas colaborativas de trabajo". (HARDT, Michael, y NEGRI, Antonio, Multitud, op. cit. , p. 124).

${ }^{67}$ Me remito a NEGRI, Antonio, y HARDT, Michael, Imperio, op. cit. , pp. 43-44.

${ }^{68}$ Véase HARDT, Michael, y NEGRI, Antonio, Multitud, op. cit. , pp. 181-183.

${ }^{69}$ Ibíd. , pp. 15-17.

${ }^{70}$ En ese sentido, la potencia de la multitud desborda la figura de la clase trabajadora, toda vez que ese concepto se aplicó tan sólo a los obreros industriales, mientras que la multitud mancomuna a todas las figuras multiformes involucradas en la producción biopolítica de lo común. (Ibíd. , pp. 16-17).

${ }^{71}$ Me remito a VIRNO, Paolo, Cuando el verbo se hace carne. Madrid, proyecto editorial Traficantes de sueños, 2005, pp. 179-183.

${ }^{72}$ Sostiene Virno: "Llamo natural a la historia que tiene en la naturaleza humana no sólo su recóndito presupuesto, sino también su contenido manifiesto. Son histórico-naturales, entonces, los fenómenos contingentes que revelan el invariable biológico, asegurándole por un momento una llamativa prominencia en el plano social y político”. (Ibíd. , p. 182).

${ }^{73}$ Según Virno: "En nuestra época, los requisitos biológicos del Homo Sapiens (facultad del lenguaje, no especialización, neotenia, etcétera) encajan punto por punto con las más significativas categorías sociológicas (fuerza de trabajo, flexibilidad, formación continua, etcétera)". (Ibíd. , p. 212). 
presencia perpetua del ser de los singulares y perduración de la potencia inmanente en los muchos; finalmente, el proyecto político de una multitud que ha de emerger mediante la decisión absoluta de los muchos y en tanto que afirmación de una democracia radical ${ }^{74}$. En ese sentido, ¿cuál es la ontología constituyente de este sujeto postfordista multitudinario? Y, ¿de qué manera la multitud, ese sujeto y creación de la praxis común, expresa la potencia de una forma de vida radicalmente democrática, capaz de consumar el proyecto democrático inacabado de la modernidad? Desde luego, para entender cabalmente la multitud histórico-política que comienza a expresarse tendencialmente en la forma de vida postfordista, hay que elucidar la constitución ontológica de la multitud como potencia absoluta de lo común y diferencia irreducible de lo singular. En tanto que es carne social viviente o inteligencia genérica encarnada y distribuida en la producción de lo común, hay que partir señalando que la multitud no se deja clausurar como un cuerpo político unitario o como un organismo jerarquizado de funciones localizadas ${ }^{75}$. La multitud corresponde a un cierto exceso, apertura y exuberancia ontológica: emerge a través del juego expansivo y del dinamismo constituyente entre lo común y lo singular, sin que podamos encuadrarla en la representación de la identidad y/o la diferencia ${ }^{76}$. No en vano, la multitud expresa la multiplicidad de las singularidades, que no es representable como una identidad única, ni traducible a la indiferenciación de las diferencias; de ese modo, la actuación mancomunada de las singularidades, para producir lo común sin dejar de constituir diferencias individuales, no puede asimilarse ni con la identidad del "pueblo", ni con la uniformidad informe de la "masa", la multiplicación de las singularidades, así como su composición abierta y plural, es el modo inmanente de constitución de una subjetividad tan multiforme como potente, abocada a producir lo común y a originar nuevas experiencias de cooperación y comunicación.

Ciertamente, en el cuerpo político moderno del estado-nación, se procuró subordinar la multiplicidad de las singularidades bajo la unidad de la representación y la identidad del "pueblo". No en vano, la tradición de la teoría política occidental parece haber asumido como ontología social implícita que sólo el "Uno" puede gobernar (ya sea el "pueblo" u otro sujeto único). Pero la trampa inherente a una concepción del poder soberano como gobierno de lo "Uno" consiste en terminar reduciendo la multiplicidad de las singularidades a un cuerpo político tan soberano como clausurado ${ }^{78}$. Ahora bien, esa multiplicidad de singularidades agentes y de diferencias irreductibles que es la multitud, en tanto que potencia inmanente y autoorganización de una vida en común, no se deja representar como un cuerpo político unificado bajo la voluntad soberana o el interés general del pueblo ${ }^{79}$. En suma, la potencia ontológica subyacente a la producción de lo común y a la comunicación de los singulares, se expresa cabalmente más allá del orden de la representación y, por tanto, en abierta oposición a la identidad del "pueblo", esa construcción del estado-nación moderno. La multitud se presenta, pues, como ese modo de ser de la multiplicidad de los singulares que persiste en su diferencia irreducible, a través de la producción de lo común, en la acción colectiva y la escena pública ${ }^{80}$. En ese sentido, el ser en

\footnotetext{
${ }^{74}$ Véase HARDT, Michael, y NEGRI, Antonio, Multitud, op. cit. , pp. 258-259 y 395-399.

${ }^{75}$ Me remito a NEGRI, Antonio, Guias, op. cit. , pp.131-137. Véase, también, HARDT, Michael, y NEGRI, Antonio, Multitud,, op. cit. , pp. 189-192 y 224-228. A partir de la contraposición entre cuerpo y carne sociales, sostienen Hardt y Negri: "La multitud viene a ser como carne excepcional que rechaza la unidad orgánica del cuerpo". (Ibíd., p. 192). En ese sentido, la carne de lo social es potencia simbiótica, a lo sumo susceptible de componer un cuerpo metamórfico; pero, la multitud no está condenada a permanecer informe, sino que puede autoorganizarse en un nuevo cuerpo democrático: "En cualquier caso, si la multitud ha de formar un cuerpo, será necesario que permanezca siempre y necesariamente como una composición abierta y plural, no como un todo unitario dividido en órganos jerarquizados". (Ibíd. , p. 225).

${ }^{76}$ Según Hardt y Negri: "En términos conceptuales, la multitud sustituye el par contradictorio identidad/diferencia por el par complementario comunalidad/singularidad". (Ibíd. , p. 255).

77 Ibíd. , pp. 16-17.

${ }^{78}$ Ibíd. , pp. 374-375.

${ }^{79}$ Ibíd. , pág. 128.

${ }^{80}$ Véase VIRNO, Gramática de la multitud, op. cit. , pp. 21-22.
} 
común de los muchos tiene la peculiaridad de que no se puede dominar con los cortes entre lo público y lo privado, o entre lo individual y lo colectivo, situando simplemente a la multitud de los singulares del lado de lo privado o lo individual; y es que la constitución ontológica de la multitud atraviesa estas duplas, que parecen haber sido concebidas precisamente para acotar y domesticar tanto el exceso de diferencia, como la red irrepresentable de singularidades que los muchos encarnan ${ }^{81}$. De hecho, la multitud despliega una potencia inmanente y una forma de existencia política que resultan absolutamente heterogéneas con respecto al orden de la representación estatal y sus distinciones institucionales. Por eso, la multitud no se deja representar en una voluntad general, ni concreta pactos, ni transfiere derechos al soberano: ya comparte un intelecto general, una red cooperativa y una subjetividad biopolítica, a través de la producción de lo común ${ }^{82}$.

La potencia constitutiva de la multitud y el ejercicio compartido del intelecto general abren la perspectiva de una experiencia democrática radicalmente diferente, a saber, la irrupción de una esfera pública no estatal, siempre y cuando el intelecto público devenga "república", comunidad política de los muchos ${ }^{83}$. En ese sentido, la multitud postfordista, que ya aparece involucrada en la producción biopolítica y en la expansión de lo común, autoorganizándose como una red abierta de singularidades, expresa la posibilidad más señera de una democracia radical en la actualidad ${ }^{84}$. De ese modo, podemos concluir que la producción de la vida en común y el ejercicio del intelecto general han de devenir, incluso más que res publica, una res communis, que no se deja cosificar ${ }^{85}$. Ahora bien, la emergencia de un proyecto de democracia radical multitudinaria enfrenta una cierta encrucijada: al tiempo que se trata de afirmar absolutamente la potencia constituyente de la multitud, así como de desplegar la movilización autónoma de los muchos; simultáneamente, la democracia parece adoptar la forma de una sustracción y un movimiento centrífugo, un éxodo y una huida de la red de biopoderes del nuevo orden imperial. De esa manera, la democracia multitudinaria no sólo pasa por configurar el éxodo como una resistencia reticular, sino, además, por transformar la resistencia en poder constituyente y creación de formas de vida alternativas ${ }^{86}$. No en vano, en este proyecto democrático de la multitud se está creando constantemente una subjetividad política antagónica, que no se limita a reivindicar la diferencia singular dada; más bien, se trata de que toda singularidad se exponga a su propia autotransformación, a la hibridación y mestizaje de su propia diferencia radical. La producción antagónica de un sujeto político multitudinario no consiste tanto en aceptar las diferencias dadas, cuanto en hacernos diferentes actuando en común.

No es de extrañar que los teóricos de la democracia radical multitudinaria hayan matizado su proyecto, ora enfatizando el poder constituyente y la potencia autoorganizadora de la multitud, ora insistiendo en el éxodo y defección multitudinarios. No cabe duda de que -en la propuesta de Negrila democracia se vincula al poder constituyente y a la creatividad del ser social, esto es, a la potencia inmanente y a la expresión múltiple de la multitud, al deseo de ser en común y a la cooperación de los singulares; de hecho, - para Negri-la democracia no es sino el autogobierno de la multitud y la afirmación absoluta de la potencia ontológica de una multiplicidad de singularidades cooperantes: el procedimiento absoluto de una constitución radical del mundo de vida y de la innovación del ser en común ${ }^{87}$. De ese modo, el poder constituyente no sólo se perfila como la matriz de lo político, entendido en tanto que producción ontológica del ser en común; además, corresponde a esa apuesta democrática, consistente en una afirmación absoluta de la potencia ontológica de la multitud (que desborda

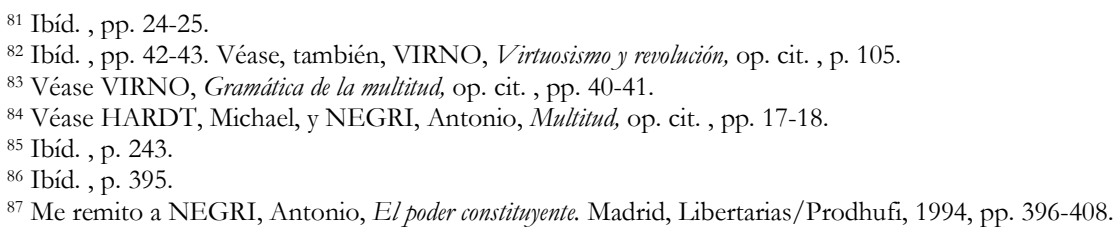


tanto la limitación constitucional, como la unificación de la soberanía) ${ }^{88}$. Se trata, en suma, de radicalizar la democracia como proyecto de la multitud y, por tanto, de expresar todo el poder constituyente del sujeto político democrático, de manera que la producción de lo político corresponda a la autoinvención de lo social. De hecho, estamos hablando de la creación democrática de derecho, igualdad y participación, o, en otras palabras, de expandir la autonomía potencial de la multitud. Y, más concretamente, lo que está en juego - para Negri y Hardt- es el automovimiento sin restricciones de la multitud, la apropiación social de la riqueza común, así como la reapropiación pública del intelecto general ${ }^{89}$. Por otra parte, Negri y Hardt vinculan la potencia democrática de la multitud a la producción de una subjetividad antagónica, que se expresa en la voluntad de estar en contra, como nomadismo, deserción y éxodo ${ }^{90}$. En mayor medida aún, la propuesta por parte de Virno de una democracia radical multitudinaria, esto es, de una esfera pública no estatal, recibe su principal impulso del movimiento centrífugo de los muchos, del éxodo y de la desobediencia civil. En ese sentido, resistencia y desobediencia civil, éxodo y defección, son - para Virno- los índices alusivos y las formas señeras de la acción política de la multitud contemporánea; constituyen opciones radicales que expresan tanto un virtuosismo republicano no servil, cuanto el exceso de potencia e ingenio del ser en común multitudinario ${ }^{91}$. En suma, éxodo y desobediencia civil no serían actos simplemente negativos, sino una modificación creadora de las condiciones del ser en común ${ }^{92}$.

\section{Conclusión: las encrucijadas de la democracia radical.}

Sin duda, las propuestas contemporáneas de democracia radical parecen compartir tantos parecidos de familia, como diferencias decisivas. Pero, en todo caso, cabe vincularlas como variaciones de un proyecto amplio de radicalización de la democracia, pues el modo en que conciben la profundización de la revolución democrática no pasa tanto por los procedimientos formales, por los mecanismos de representación o por la simple extensión de la participación en la vida institucional, cuanto apunta a la constitución ontológica del sujeto político democrático y a la redescripción e innovación de las identidades políticas, a través de las prácticas democráticas. Además, las distintas propuestas de democracia radical le reconocen un lugar constitutivo al conflicto en la vida democrática, toda vez que asumen que el sujeto político se construye a través de complejos procesos de producción antagónica de subjetividad, así como mediante las luchas agonísticas en el espacio público. En ese sentido, podríamos sintetizar el proyecto compartido de las distintas propuestas de democracia radical: su principio decisivo es que no hay democracia sin autoconstitución de un sujeto político, sin reinvención de las identificaciones y las singularidades, pero, tampoco, sin expresión de esa diferencia interna que es constitutiva de lo social. Y es que el sujeto democrático radical ejerce su singular virtud cívica a través de la puesta en común de las demandas sociales, multiplicando los contrapoderes y posiciones antagónicas de sujeto, así como abriendo litigiosamente las opciones de nuestro ser en común. En suma, la democracia radical se justifica como revolución democrática permanente, asunción de la indeterminación radical de la forma de vida democrática y constante autoinstitución de nuevos modos sociohistóricos de convivir.

Ahora bien, existen divergencias notables entre las dos variantes de la democracia radical que hemos presentado; sobre todo, cuando se trata de concebir el modo en que tiene lugar la constitución del sujeto político democrático: como construcción político-discursiva del "pueblo", o como autoor-

\footnotetext{
${ }^{88}$ Ibíd. , pp. 404-405. Véase, también, HARDT y NEGRI, Multitud,, op. cit. , pp. 398-399.

${ }^{89}$ Me remito a NEGRI, Antonio, y HARDT, Michael, Imperio, op. cit. , pp. 360-372.

${ }^{90}$ Ibíd. , pp. 199-206. Véase, también, HARDT y NEGRI, Multitud, op. cit. , pp. 379 y 388-389.

${ }^{91}$ Me remito a VIRNO, Gramática de la multitud, op. cit. , pp. 70-73.

${ }^{92}$ Véase VIRNO, Virtuosismo y revolución, op. cit. , p. 122.
} 
ganización inmanente de la "multitud". Por una parte, las propuestas de democracia radical pluralista sostienen que el sujeto político se construye siempre a través de la inscripción hegemónica de ciertos significantes (como el "pueblo"), que articulan las demandas sociales particulares, por más que se trate únicamente de una estabilización frágil de las identificaciones, siempre expuestas tanto a ulteriores redescripciones identitarias, como al desplazamiento en las fronteras del antagonismo social y a la irrupción de nuevas posiciones antagónicas de sujeto. Por otra parte, el proyecto de una democracia radical multitudinaria considera que el sujeto político se constituye (ontológica, sociológica y políticamente) en tanto que potencia inmanente de la multitud, como producción antagónica del ser en común y afirmación absoluta de la multiplicidad de los singulares, más allá del orden de la representación; se trata, pues, de un sujeto político reticular y distribuido, sin más identidad que el hacerse diferente, hibridándose e inventándose en común.

Desde luego, las divergencias a la hora de pensar la constitución del sujeto político se entienden cabalmente cuando revisamos ciertas diferencias de fondo en la manera de concebir la ontología de lo social. En los teóricos de la democracia radical multitudinaria se presupone cierta ontología de la potencia, que es tanto una afirmación del ser deseante y de la fuerza productiva del ser social, cuanto una apertura a lo potencial, es decir, al dinamismo constitutivo del hacer ser y del crear opciones de porvenir $^{93}$. Por otra parte, la democracia radical multitudinaria establece una ontología social tan inmanentista como materialista, conforme a la cual la constitución de la subjetividad no es atribuible a ninguna causa externa o principio trascendente del ser social; surge únicamente de la interacción deseante que les permite a las singularidades construirse a sí mismas y componerse, autoorganizándose directamente, en virtud de la propia eficacia material de las relaciones que sostienen su ser en común ${ }^{94}$. Pues bien, frente a esta ontología de la producción deseante y de la potencia inmanente, que parece dar por hecho que existe una tendencia espontánea a la convergencia del ser social en común (sin necesidad de construcción política o articulación hegemónica, y por el simple hecho de compartir la voluntad de estar en contra), propuestas de democracia radical como la de Laclau estipulan el carácter decisivo de la articulación político-discursiva, cuando se trata de concebir la construcción política del sujeto, a partir de la heterogeneidad de las demandas sociales ${ }^{95}$. No en vano, Laclau considera que la ontología de lo social no se estructura como inmanencia radical, sino en tanto que trascendencia fallida, esto es, plenitud ausente, indeterminación e indecidibilidad de lo social, que sólo puede resultar construido discursivamente, articulado políticamente e investido hegemónicamente ${ }^{96}$. En suma, los teóricos de la democracia radical y plural parecen asumir cierta perspectiva deconstructivista, según la cual la indecidibilidad opera en la construcción de cualquier forma de objetividad, toda vez que la diferencia y la exterioridad constitutiva de los significantes son la condición aporética de posibilidad de cualquier totalización o unificación del sentido social ${ }^{97}$.

Por cierto, las divergencias en la ontología de lo social se refuerzan a través de diferencias significativas a la hora de concebir la eficacia del discurso y la facultad lingüística, que sustentan tanto la expresión de lo social, cuanto la construcción del espacio público. Los teóricos de la democracia radical y plural parten de una concepción del campo socio-político en tanto que construcción discursiva, a la vez que aportan una caracterización estructural del discurso como sistema de diferencias; pero, cuando se trata de dar cuenta de la articulación del sentido, también recurren a cierta "arqueología" del discurso, la cual les permite apreciar los procedimientos de formación de enunciados, los modos de

\footnotetext{
${ }_{93}^{3}$ Sin duda, se trata de una ontología de marcada ascendencia spinoziana. Véase NEGRI, Antonio, La anomalía salvaje. Barcelona, Anthropos, 1993, pp. 366-374.

${ }^{94} \mathrm{El}$ materialismo histórico se redescribe, pues, en clave deleuziana y spinoziana. Me remito a NEGRI, Antonio, Guías, op. cit. , pp. 113-115.

${ }_{95}$ Véase LACLAU, La razón populista, op. cit. , pp. 298-300.

${ }^{96}$ Ibíd. , p. 303.

${ }^{97} \mathrm{La}$ inspiración derrideana es incuestionable. Véase MOUFFE, La paradoja democrática, op. cit. , pp. 146-148.
} 
regular la producción de objetividad y, en suma, la estratificación y dispersión regulada de los elementos del sentido ${ }^{98}$. De esa manera, - para Laclau y Mouffe - todo intento de clausura discursiva de lo social se ve inevitablemente expuesto a su propia deconstrucción, en la medida en que cualquier construcción discursiva resulta desbordada tanto debido al carácter diferencial y diferido de toda producción de sentido, como por la intertextualidad y exterioridad constitutivas que atraviesan todo discurso, siempre expuesto al juego indecidible de los significantes ${ }^{99}$. Según Mouffe, esta indecidibilidad radical del sentido socio-discursivo se ve remarcada a través de la pluralidad de los juegos del lenguaje, así como debido a la inconmensurabilidad de los léxicos en que se articulan y redescriben nuestras prácticas comunes, los cuales siempre están arraigados en el trasfondo de una forma de vida compartida particular, sin que podamos disponer de un metalenguaje universal libre de contexto ${ }^{100}$. Como contrapartida, entre los teóricos de la democracia radical multitudinaria, la caracterización del discurso pone más énfasis en esa potencia realizativa del lenguaje, que produce y sostiene las interacciones en el espacio político de aparición. En ese sentido, Virno parte del hecho de que todo enunciar es un hacerdecir (el hecho de hablar), y considera que la clave de la significación lingüística radica no tanto en el contenido representado (lo que se dice), cuanto en la performatividad absoluta de toda manifestación del sentido, esto es, en el evento de poder-decir, en el acontecimiento de tomar la palabra, ejercer la potencia del decir, comunicar que se está comunicando y poner en escena la praxis comunicativa ${ }^{101}$. Por lo demás, - para Virno- este performativo absoluto, el hecho de tomar la palabra, constituye el modelo de toda actividad virtuosa, o sea de toda acción sin más obra que la exposición del agente entre los otros; de ahí la potencia público-política del lenguaje, como facultad de iniciar la locución, revelarse como agente y aparecer en común ${ }^{102}$. En suma, Virno se centra en la decibilidad más que en la indecidibilidad del discurso; no en vano la autoproducción inmanente del sentido social y la constitución de una esfera pública de aparición, más allá del orden de la representación, pasan no tanto por la red ilimitada de las referencias intertextuales, cuanto por la manifestación expresa de la potencia genérica del decir, o sea por la encarnación del hablar y por la irrupción de la voz significante.

Precisamente, estas divergencias a la hora de concebir el discurso, ora como intertextualidad indecidible, ora como performatividad absoluta, se traducen en distintas perspectivas ante el orden de la representación y ante el problema de la representación política. Desde el punto de vista de los teóricos de la democracia radical multitudinaria, la facultad genérica del poder-decir, que se encarna singularmente en las voces significantes, posibilita una exposición en común, más allá del orden de la representación. Así, pues, la potencia del lenguaje sostiene una esfera pública que no es sino expresión plural de las voces significantes y acción comunicativa común, no mediada por el orden de la representación. En ese sentido, no es de extrañar que las propuestas de democracia radical multitudinaria expresen una marcada desconfianza hacia los mecanismos de la representación, pues los consideran una manera de neutralizar tanto la potencia de la multitud, como la pluralidad de voces singulares que constituyen el ser en común de lo social. Negri y Hardt, por ejemplo, sostienen que la representación, en cualquiera de sus formas (decidir por los representados, elegir representantes, o que los representados controlen a los representantes), conforma una relación dual y paradójica, la cual conecta a representados y representantes, pero al mismo tiempo los separa. Por tanto, -para Negri y Hardt- la representación consiste en un mecanismo de síntesis disyuntiva o de relación en la separación, plenamente funcional al gobierno de lo Uno y a la unificación de la soberanía; de hecho, constituye una trampa

${ }_{98} \mathrm{El}$ estructuralismo saussureano coexiste, pues, con una concepción del discurso netamente foucaultiana. Véase LACLAU y MOUFFE, Hegemonía y estrategia socialista, op. cit. , pp. 119-123.

${ }^{99}$ Ibíd. , pp. 128-130.

${ }^{100}$ Se trata de un argumento wittgensteiniano, con pinceladas rortyanas, que tiene interesantes repercusiones políticas. Véase MOUFFE, La paradoja democrática, op. cit. , pp. 76-81.

${ }_{101}$ Me remito a VIRNO, Paolo, Cuando el verbo se hace carne. Madrid, proyecto editorial Traficantes de sueños, 2005, pp. 61-73.

102 Ibíd. , pp. 48-59. 
tendida para limitar la afirmación absoluta del autogobierno democrático de todos por todos ${ }^{103}$. Por el contrario, teóricos de la democracia radical y plural, como Laclau, si bien reconocen la paradoja de la representación (esto es, la intransparencia, suplementariedad e indecidibilidad del representante), y asumen que la representación es un proceso bidireccional (del representante al representado, y del representado al representante), sostienen, además, que cualquier institución de lo social pasa inevitablemente por la representación, esto es, requiere de la articulación de significantes capaces tanto de homogeneizar las demandas sociales, como de construir identificaciones políticas ${ }^{104}$. En ese sentido, - para Laclau - no hay construcción de un sujeto político sin un momento de representación identificadora, que, por cierto, coincide con la redescripción de las identidades y posiciones subjetivas dadas; de hecho, la representación es el ámbito constitutivo de cualquier objetividad social ${ }^{105}$.

En ese sentido, la propuesta de los teóricos de la democracia radical pluralista no se plantea únicamente en términos antagónicos, sino como un proyecto hegemónico para la reconstrucción positiva de la dirección institucional, por muy inestable que pueda resultar su ordenamiento, debido a la lógica subversiva que la revolución democrática inscribe en lo social. Y es que la democracia radical y plural persigue articular una nueva hegemonía e institucionalizar cierto equilibrio inestable, por más que éste siempre permanezca expuesto a cierta tensión constitutiva entre la radicalización plural de las demandas democráticas y, por otra parte, la construcción estratégica de un ordenamiento político ${ }^{106}$. No es de extrañar, por tanto, que Laclau le haya reprochado a los teóricos de la democracia radical multitudinaria cierto oportunismo táctico carente de estrategia, basado sobre todo en la multiplicación de las resistencias antagónicas y en la convergencia espontánea de las luchas, en torno a la inespecífica voluntad de estar en contra, sin determinar el modo de construcción política del sujeto antagonista ${ }^{107}$. En todo caso, en la perspectiva de Negri y Hardt, por más que se privilegien las resistencias antagónicas, las experiencias de éxodo y las líneas de fuga del sistema, sí se establece un proyecto de organización política absolutamente democrática, que los autores consideran acorde a la eficacia de la situación actual (a la oportunidad histórica, a las formas de producción social y a las posibilidades de cumplimiento de una democracia plena); se trata de una estructura organizativa distribuida en redes, que no se limita a la creación de contrapoderes y resistencias, sino que genera un movimiento de movimientos, capaz de articular la expresión de la autonomía, con la producción de lo común ${ }^{108}$. Esta democracia en red crea cooperación autoorganizada, y produce subjetividad política, a partir de la propia deconstrucción de las condiciones estructurales del capitalismo postfordista, que ya acumula valor reticularmente, a través del intelecto general, de la cooperación social y de la producción biopolítica, aunque sea bajo la forma paradójica de un "comunismo del capital"109. En ese sentido, el proyecto de democracia radical multitudinaria no parece reducirse a la mera táctica espontánea, aunque sí se distancia marcadamente de toda homogeneización institucional sobrepuesta a la expresión heterogénea de los singulares.

Hasta este momento, hemos puesto de manifiesto las convergencias y divergencias en lo que hemos caracterizado como dos modelos de democracia radical. Pero, al cabo de este recorrido por las versiones pluralista y multitudinaria del proyecto de una democracia radical, se hace preciso aclarar que no ha sido nuestro propósito forzar una elección tan especulativa como concluyente; de hecho, la decisión teórico-práctica por un determinado proyecto de construcción de la democracia lleva la marca del kairós, y resulta inevitablemente apremiada por contingencias y coyunturas que seleccionan

\footnotetext{
103 Véase HARDT, Michael, y NEGRI, Antonio, Multitud, op. cit. , pp. 278-285.

104 Véase LACLAU, La rąón populista, op. cit. , pp. 199-207.

105 Ibíd. , p. 206.

${ }^{106}$ Véase LACLAU y MOUFFE, Hegemonía y estrategia socialista, op. cit. , pp. 212-213.

${ }^{107}$ Me remito a LACLAU, La razón populista, op. cit. , pp. 300-301.

${ }^{108}$ Véase HARDT, Michael, y NEGRI, Antonio, Multitud, op. cit. , pp. 116-119.

${ }^{109}$ Me remito a VIRNO, Gramática de la multitud, op. cit. , pp. 116-118.
} 
eventualmente el modo de subjetivación política más acorde con las circunstancias. Por nuestra parte, tan sólo pretendíamos testimoniar la profundidad, diversidad y productividad de las propuestas de radicalización de la democracia, justamente en un momento en que el tan mediatizado nihilismo político convive con los cantos de sirena de la nueva derecha y con los triunfales despropósitos del pensamiento único. Por lo demás, a pesar de sus productivas diferencias, las distintas propuestas de democracia radical asumirían que este enriquecimiento ontológico y discursivo que despliega la revolución democrática (la multiplicación de modos sociales de ser, de identificaciones cruzadas y de encrucijadas de decisión antagónica) invita, de hecho, a la expresión plural e incluso paradójica de las distintas vías de radicalización de la apuesta democrática, que no es sino esa paradoja de la autoinstitución de lo común. En ese sentido, nuestra exposición teórica no tiene mayor justificación que la propia apuesta democrática, a saber: hacer productivo el antagonismo y poner en común la diferencia. 